Www.jmscr.igmpublication.org

Impact Factor (SJIF): 6.379

Index Copernicus Value: 79.54

ISSN (e)-2347-176x ISSN (p) 2455-0450

crossrefDOI: https://dx.doi.org/10.18535/jmscr/v6i10.154

Journal Of Medical Science And Clinical Research

IGM Publication

An Official Publication of IGM Publication

\title{
The prevalence of hypothyroidism in patients with gall stone disease
}

\author{
Authors \\ Dr Ahmed Hasan Issa ${ }^{1}$, Dr Mohammed Mosa Mohammed ${ }^{2}$ \\ Dr Mohammed H. Al Jawher ${ }^{3 *}$ \\ ${ }^{1}$ M.B.CH.B, ${ }^{2}$ F.R.C.S. (Glasgow), C.A.B.S., Consultant Surgeon \\ ${ }^{3}$ F.R.C.S. (Glasgow), C.A.B.S., Professor of General Surgery \\ ${ }^{1,2}$ Department of Surgery, Basrah Teaching Hospital, Basrah, Iraq \\ ${ }^{3}$ Department of Surgery, College of Medicine, University of Basrah, Basrah, Iraq \\ *Corresponding Author
}

Prof. Mohammed H. Al-Jawher

Email: mohaljawher@yahoo.com

\begin{abstract}
Background: There was a debate whether hypothyroidism could lead to cholelithiasis over the last few decades. Recent studies showed that disturbances in lipid metabolism combined hypothyroid status, particularly of a cholesterol pathway and changes in the rate of bile excretion which could lead to the formation of gall stones. Recently, the pro-relaxing effect of serum total thyroxin (T4) on both human and pig sphincter of Oddi (SO) has been proven.

Objective: To assess the prevalence of hypothyroidism in patients with gall stones and try to establish hypothyroidism as a possible etiological factor for gallstones formation.

Methods: A cross sectional study was carried on in Basrah Teaching Hospital involving a 232 patients with gallstones whom admitted to the hospital during the period from April 2016 to October 2017. All patients were assessed by detailed clinical history and examination with appropriate investigations in form of abdominal USS, thyroid function tests and lipid profile.

Results: Out of 232 patients of gallstone, 200 patients were euthyroid and 32 patients were hypothyroidism, 22 patients were diagnosed as subclinical hypothyroidism and 10 patients were diagnosed as clinical hypothyroidism. Regarding lipid profile, $175(75.4 \%)$ of patients with gall stone had increased lipid profile, while 57(24.6\%) had normal lipid profile.

Conclusion: Hypothyroidism which may lead to elevation of serum lipid profile and thus act as a cause of gall stone formation.

Keywords: Gall stone disease, Hypothyroidism, Prevalence.
\end{abstract}

\section{Introduction}

There has been a discussion for decades, whether thyroid disorders could cause gallstone disease. Gall stones constitute a significant health problem in developed societies, affecting $10 \%$ to $15 \%$ of the adult population ${ }^{1}$.
The pathogenesis of cholelithiasis appears to be multifactorial $^{2,3}$. It has been shown that disturbances in lipid metabolism that occur during hypothyroidism, particularly cholesterol pathway, changes in the rate of bile excretion lead to the formation of gall stones. Recently, the pro- 
relaxing effect of serum total thyroxin (T4) on both human and pig sphincter of Oddi (SO) has been proven ${ }^{4}$.

Lack of T4 may possibly contribute to SO contractility which in turn not only disturbs the normal bile flow but also prohibits the passage of stones formed in the gallbladder to the duodenum. $^{5}$

Previous studies that investigated the association between thyroid function and gall stone disease in human beings had a lot of bias produced false positive results. Furthermore, the statistical analyses were only controlled for age, but not for further confounders ${ }^{6,7}$.

Many studies were done to identify risk factor for gall stones in the west have focused on hypersaturation of cholesterol at the bile in nucleation process as a critical step in the genesis of bile stone ${ }^{8}$. Therefore, the aim of the study is to assess the prevalence of hypothyroidism in patients with gall stones and try to establish hypothyroidism as a possible etiological factor for gall stones formation.

\section{Patients and Methods}

The present study has been done in the Department of Surgery at Basrah Teaching Hospital over a period of eighteen months from April 2016 to October 2017.

A cross-sectional study of 232 cases with gall stones. The selection of the sample based on research judgment [non probability (purposive) sampling method] and studied in detail clinically. Full history and clinical examination was performed with special emphases on signs and symptoms of hypothyroidism in addition to an investigations in form of USS abdomen, thyroid function tests and lipid profile were done. Patients with a serum level TSH of $0.5-4.9 \mathrm{~m}$ IU/L was considered as normal. Serum level TSH of $5-10$ $\mathrm{m} \mathrm{IU/L}$ with normal T3, T4 level is considered as subclinical hypothyroidism. Levels of TSH > 10 $\mathrm{m}$ IU/L is considered as clinical hypothyroidism. Subclinical hypothyroidism is defined as peripheral thyroid hormone levels that are within the normal range in the presence of mildly elevated serum TSH (between 5 to $10 \mathrm{Mu} / \mathrm{ml}$ ). Hypothyroidism is characterized by an elevated TSH of over $10 \mathrm{Mu} / \mathrm{ml} .7 \mathrm{In}$ case of borderline TSH levels, serum T4 and patients' symptoms were used to determine thyroid function. In our study, total serum cholesterol and serum triglyceride were estimated. Dyslipidemia was defined as serum cholesterol more than $200 \mathrm{mg} / \mathrm{dl}$ and TG more than $150 \mathrm{mg} / \mathrm{dl}$.

Patients with such conditions were excluded from the study:

- Patients on drugs causing hypothyroidism.

- Patient on drugs causing gall stones.

- History of haemolytic diseases.

- Patients with concomitant comorbidities.

-Women taking oral contraceptive pills.

All the patients were worked up and assessed according to the following protocol.

- Detailed history.

- Complete clinical examination.

- Thyroid function tests (FT3, FT4, TSH).

- Serum cholesterol.

- Serum triglyceride.

- abdominal USS.

\section{Statistics}

The data collected using and analysed a SPSS version 20. Bivariate analyses and Chi square test was used. $P$ value of $\leq 0.05$, Chi-square $\geq 5.6$ and Degree of freedom $\leq 2$ considered statistically significant.

\section{Results}

Table 1 shows the relation of hypothyroidism with gall stone, 200 patients (86.2\%) was euthyroid, while subclinical hypothyroidism was 22 patients (9.5\%) followed by clinical hypothyroidism 10 patients $(4.3 \%)$. $\mathrm{P}$ value showed an association of hypothyroidism in patients with gall stone. 
Table 1: Prevalence of subclinical and clinical hypothyroidism in patients with gall stone

\begin{tabular}{|l|c|c|}
\hline Diagnosis & Number & Percentage (\%) \\
\hline Euthyroid & 200 & 86.2 \\
\hline $\begin{array}{l}\text { Subclinical } \\
\text { hypothyroidism }\end{array}$ & 22 & 9.5 \\
\hline Clinical hypothyroidism & 10 & 4.3 \\
\hline Total & 232 & 100 \\
\hline
\end{tabular}

$\mathrm{X}^{2}=292.7$, degree of freedom $=2, \mathrm{p}$ value 0.0001 .

The prevalence of increased lipid profile in patients with gall stone 175 (75.4\%), while patients with normal lipid profile were 57(24.6\%). $\mathrm{P}$ value indicates that increased lipid profile as a risk factor for gall stone disease (Table 2).

Table 2: Prevalence of lipid profile among patients with gall stone

\begin{tabular}{|l|c|c|}
\hline Laboratory results & Frequency & $\begin{array}{c}\text { Percentage } \\
(\boldsymbol{\%})\end{array}$ \\
\hline normal lipid profile & 57 & 24.6 \\
\hline Increase lipid profile & 175 & 75.4 \\
\hline Total & 232 & 100.0 \\
\hline
\end{tabular}

$\mathrm{X}^{2}=60$, degree of freedom $=1, \mathrm{p}$ value 0.0001 .

The Distribution of gender and thyroid function in gall stone patients is shown. No association was found between gender and thyroid function with $\mathrm{p}$ value of 0.553 . Female patients were high euthyroid status (160), hypothyroidism were (26). While male patients euthyroid state were (40), hypothyroidism (6).

Table 3: Distribution According to gender and thyroid function in gall stone patients

\begin{tabular}{|l|c|c|c|}
\hline \multirow{2}{*}{ Gender } & \multicolumn{2}{|c|}{ Thyroid function } & \multirow{2}{*}{ Total } \\
\cline { 2 - 3 } & Euthyroid & Hypothyroidism & \\
\hline Male & 40 & 6 & 46 \\
\hline Female & 160 & 26 & 186 \\
\hline & 200 & 32 & 232 \\
\hline
\end{tabular}

Chi square $=1.185$, degree of freedom $=2, \mathrm{p}$ value 0.553 .

Lipid profile at the age $\leq 30$ there was 10 patients with normal lipid profile and 24 patients with normal lipid profile \& patient within age group 31-40 years had 12 with normal lipid profile and 54 with increase lipid profile, while patients within age group 41-50 years had 21 with normal lipid profile and 59 with elevated lipid profile, last age group were taken to 60 years showed 10 patients with normal lipid profile and 42 with elevated lipid profile (Table 4).

Table 4 Distribution of lipid profile within studied age groups

\begin{tabular}{|l|c|c|c|}
\hline \multicolumn{2}{|l|}{ Lipid profile } & \multirow{2}{*}{ Total } \\
\cline { 1 - 2 } Age & $\begin{array}{c}\text { Normal lipid } \\
\text { profile }\end{array}$ & $\begin{array}{c}\text { Increase } \\
\text { lipid profile }\end{array}$ & \\
\hline$\leq \mathbf{3 0}$ & 10 & 24 & 34 \\
\hline $\mathbf{3 1 - 4 0}$ & 12 & 54 & 66 \\
\hline $\mathbf{4 1 - 5 0}$ & 21 & 59 & 80 \\
\hline $\mathbf{5 1 - 6 0}$ & 10 & 42 & 52 \\
\hline Total & 53 & 179 & 232 \\
\hline
\end{tabular}

Chi - square $=1.374$, degree of freedom $=2, \mathrm{P}$ value 0.5

There was no significant relationship between gender and lipid profile, 11 male patients had normal lipid profile while 35 males had elevated lipid profile, regarding female patients 140 of them had elevated lipid profile while 46 had normal lipid profile (Table 5).

Table 5: Distribution of lipid profile among studied male and female groups

\begin{tabular}{|l|c|c|c|}
\hline Lipid profile & \multirow{2}{*}{ Total } \\
\cline { 1 - 3 } Gender & $\begin{array}{c}\text { Normal lipid } \\
\text { profile }\end{array}$ & $\begin{array}{c}\text { Increase lipid } \\
\text { profile }\end{array}$ & \\
\hline Male & 11 & 35 & 46 \\
\hline Female & 46 & 140 & 186 \\
\hline Total & 57 & 175 & 232 \\
\hline
\end{tabular}

Chi - square $=0.013$, degree of freedom $=1, \mathrm{P}$ value 0.9 .

The table 6 shows no correlation between thyroid function and lipid profile in patients with gall stone ( $p$ value .917), majority of patients in our study had elevated lipid profile, 150 of them had euthyroid, 25 with hypothyroidism. The other 57 patients with normal lipid profile, 50 of them euthyroid, 7 with hypothyroidism.

Table 6: Distribution according to lipid profile and thyroid function in gall stone patients

\begin{tabular}{|l|c|c|c|}
\hline Lipid profile & \multicolumn{2}{|c|}{ Thyroid function } & \multirow{2}{*}{ Total } \\
\cline { 2 - 3 } & Euthyroid & $\begin{array}{c}\text { Hypothy } \\
\text { roidism }\end{array}$ & \\
\hline $\begin{array}{l}\text { Normal lipid } \\
\text { profile }\end{array}$ & 50 & 7 & 57 \\
\hline $\begin{array}{l}\text { Increased lipid } \\
\text { profile }\end{array}$ & 150 & 25 & 175 \\
\hline & 200 & 32 & 232 \\
\hline
\end{tabular}

Lipid profile was in form of triglyceride and total cholesterol level.

Chi - square $=0.173$, degree of freedom $=2, \mathrm{P}$ value 0.917 


\section{Discussion}

The present study has investigated the possible relationship between gall stone disease and hypothyroidism. Earlier studies had shown an association between hypothyroidism and delayed emptying of the biliary tract, explained at least partly by the lack of pro relaxing effect of T4 on sphincter of Oddi contractility ${ }^{7}$. In addition to disturbances of lipid metabolism that may consecutively lead to a change of the composition of the bile ${ }^{9}$. The hallmark laboratory investigation to detect hypothyroidism, also a sensitive indicator in diagnosing thyroid dysfunction at early stage is serum TSH level. Serum TSH level is the most accurate indicator of thyroid function 10,11

In this study, we found that increased age as a risk factor in gall stone disease with peak age of 41- 50 years $(34.5 \%)$. It has been found that the advanced age was an independent risk factor for cholelithiasis in males as well as females ${ }^{12}$. In a prospective study conducted by Chen CY et al ${ }^{12}$ in July 1998 in 3647 Chinese patients, factors manifesting an increase in risk for the development of gallstone disease were age $(\mathrm{p}<.05)$. Also, increased lipid profile was studied as a risk factor contributed in developing gall stone disease, which was also found by other stud in India ${ }^{15}$.

In current study, 232 patients were studied whether hypothyroidism as a possible risk factor for gall stone disease (86.2\%) were euthyroid, (13.8\%) hypothyroidism divided into subclinical hypothyroidism $(9.5 \%)$ and clinical hypothyroidism (4.3\%). The results of the current study were in agreement with a study conducted by Sundeshwari et al in $2014^{16}$ at GRH Madurai on 200 patients with gall stones. Among them, (18) patients had subclinical hypothyroidism and (6) patients had clinical hypothyroidism which was in accordance with this study. A total of $12 \%$ of gall stone patients were diagnosed to have hypothyroidism showing that there is association of hypothyroidism with gall stone disease.

The differences between sex of patients and predominated of gall stone with age, were conducted in Iraq. There were (10\%), (38\%), and $(52 \%)$ patients for low, normal and high levels of TSH respectively ${ }^{17}$.

In a study carried out in India, out of 200 cases, $41 \%$ were in the age group of 50-60 years. There were $15.5 \%$ hypothyroid, $84.5 \%$ euthyroid cases compared to $4 \%$ hypothyroid and $96 \%$ euthyroid in controls. The peak age group of cases with hypothyroidism was in the age group of 15-60 years, as results showed an increased prevalence of hypothyroidism in gall stone patients ${ }^{18}$.

In the present study, high prevalence of hypothyroidism in females as compared to males with unsignificant statistical relationship. This was in accordance with a study in Kufa, Iraq ${ }^{14}$.

A study in Taiwan, showed that patients with hypothyroidism were more prone to have high cholesterol level, which is in the line of our study, but with unstatistical association. This can be explained as thyroid hormones influence the synthesis, absorption and usage of cholesterol ${ }^{19}$.

It has been explained that there is a possibility of association between hypothyroidism and gall stone disease, including known link between thyroid dysfunction and disturbances of lipid metabolism ${ }^{20}$, in addition to the effect of thyroxine on sphincter of Oddi ${ }^{21}$.

In coclusion, hypothyroidism may lead to gall stone formation as it cause dyslipidemia and thus, thyroid function should be assessed in any gall stone patients. Lipid profile should be estimated as well which may be the cause of lithogenic bile formation and subsequently biliary stone formation. This practice is vital to avoid recurrence of biliary cholelithiasis.

\section{References}

1. Shaffer EA. Epidemiology and risk factors for gall stone disease: has the paradigm changed in the 21st century, Curr Gastroenterol Rep. 2005; 7: 132-140

2. Lambou-Gianoukos S, Heller SJ. Lithogenesis and bile metabolism. Surg Clin North Am 2008; 88: 1175-1194. 
3. Laukkarinen J, Sand J, Autio V, Nordback I. Bile duct stone procedures are more frequent in patients with hypothyroidism.A large, registry-based, cohort study in Finland. Scand J Gastroenterol 2010; 45: 70-74.

4. Inkinen J, Sand J, Arvola P, Pörsti I, Nordback I. Direct effect of thyroxin on pig sphincter of Oddi contractility. Dig Dis Sci 2001; 46: 182-186.

5. Laukkarinen J, Sand J, Aittomäki S, Pörsti I, Kööbi P, Kalliovalkama J, et al. Mechanism of the prorelaxing effect of thyroxin on the sphincter of Oddi. Scand J Gastroenterol 2002; 37: 667-673.

6. Honore LH. A significant association between symptomatic cholesterol cholelithiasis and treated hypothyroidism in women. J Med 1981; 12: 199-203.

7. Inkinen J, Sand J, Nordback I. Association between common bile duct stone and treated hypothyroidism, Hepatogastroenterol 2001; 47: 919-921.

8. Kleinero, Ramesh J,Huleihel M,Cohen Z,Mordechai S, 2002. Acomartive study of gallstone from children and adult using FTIR spectroscopy and flurorescence microscopy. BMC Gastroenterol , 2: 3-15.

9. Canaris GJ, Manowitz NR, Mayor G, Ridgway EC. The Colorado thyroid disease prevalence study. Arch Intern Med. 2000; 160: 526-534.

10. Bergman F, Vander Linden W. Further studies on the influence of thyroxine on gallstones formation in hamsters. Acta Chir Scand 1966; 131: 319-328.

11. Vassilakis JS, Nicolopoulos N. Dissolution of gallstones following thyroxine administration. A case report. Hepatogastroenterol 1981; 28(1): 60-61.

12. Volzke H, Daniel M, John U. Association between thyroid function and gall stones. World J Gastroenterol 2005; 35: 55305534.
13. Chen CY, Lu CL, Huang YS, Tam TN, Chao Y, et al. Age is one of the risk factors in developing gallstone disease in Taiwan. Age and ageing 1998; 27: 437-41.

14. Zaini HH, Zwain KM. Prevalence of hypothyroidism in patients with gallstone disease.QMJ 2009; 6: 108-117.

15. Nath k, Kumar A, Acharya J , Prevalence of Hypothyroidism in Cholelithiasis Patients in Bikaner, Rajasthan (India), Int J Med Res Prof 2017; 3(3); 65-69 .

16. Sundeswari P, Ravisankar G, Kumar S, Premnath KSG. A prospective study of hypothyroidism in diagnosed case of gallstone. J Evid Med Healthcare 2016; 3(88): 4819-4823.

17. Ibrahim SL. The impact of thyroid dysfunction and TSH on the pathogenesis of gallstone and its complication. Journal of Kufa for Nursing Science 2014; 4(1): 1-6.

18. B. Kapora, evaluation of thyroid profile in patients with gall stone disease, Volume6, Issue-2, February - 2017 • ISSN No $2277-8160$.

19. Chih-Cheng Lai, Sai-Hung Tang, Dee Pei, Cheng-Yi Wang, Yen-Lin Chen, Chung$\mathrm{Ze} \mathrm{Wu}$. et al. The Prevalence of Subclinical Thyroid Dysfunction and Its Association With Metabolic Syndrome in Taiwanese Elderly. Intern J Gerontol 2011; 5: 25-29.

20. Canaris GJ, Manowitz NR, Mayor G, Ridgway EC. The Colorado thyroid disease prevalence study. Arch Intern Med 2000;160: 526-534 .

21. Inkinen J, Sand J, Arvola P, Porsti I, Nordback I. Direct effect of thyroxine on pig sphincter of Oddi contractility. Dig Dis Sci 2001; 46: 182-186. 